\title{
Banques de données biologiques
}

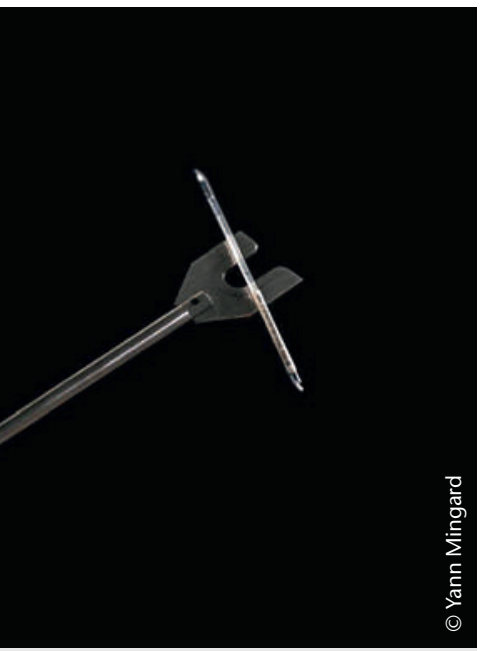

Photo de Yann Mingard: petite paille de sperme prête à être congelée dans un réservoir d'azote liquide. (Inkjet-Print, 2010).
Exposition Deposit de Yann Mingard, Musée de la photo de Winterthour, du 8 mars au 25 mai 2014.

Helmreich S. What Was Life? University of Chicago Press. www.jstor.org/stable/ 10.1086/660987

Atwood. M. Die Geschichte von Zeb. Berlin: Berlin Verlag; 2014.
Aux murs, des photos grand format. Des images sombres de matériel de laboratoire, de galeries souterraines, de citernes en acier, d'éprouvettes de sperme, d'armoires serveurs et d'étagères d'archives. L'exposition «Deposit» du musée de la photo de Winterthour présente des plantes, des animaux, des personnes et des données, le tout réparti dans quatre salles. Le photographe romand Yann Mingard tente de fixer visuellement un univers rendu la plupart du temps inaccessible et tenu à l'écart de l'opinion publique. Il expose des énigmes qui entraînent l'observateur dans un périple à travers des lieux où la vie est manipulée, codée, collectée et archivée. Un voyage à travers des chambres fortes et des bunkers, un réduit alpin détourné de son usage, des instituts de recherche et des centres de collecte de sperme, des banques de semences, des chambres de congélation, des fermes d'élevage et des bibliothèques généalogiques. Des couches du permagel arctique à l'Agroscope de Wädenswil, de l'Institut de botanique de Saint-Pétersbourg à Brest, des bananes in vitro de Leuven à Avanches, du zoo de Bâle à Nottingham, de Reykjavik à la banque suisse des cellules souches Swiss Stem Cells de Lugano ou à la banque de cellules souches familiales Future Health BioBank de Châtel-St-Denis. Dans tous ces lieux sont stockés de l'ADN, des coupes de cordons ombilicaux, des cellules, des prélèvements dentaires, des méristèmes, des prélèvements de sang et de tissus humains, du sperme et des semences végétales. Ce sont de vraies forteresses, comme celle de Swiss Fort Knox, à Saanen-Gstaad, qui gardent les mémoires de données de leurs clients avec des caméras, des systèmes antibumping et du personnel de surveillance. Le contrôle d'accès est biométrique et une surpression permanente empêche l'intrusion de particules indésirables.

Ce qui est conservé répond à des impératifs scientifiques et économiques. Comme dans les banques financières, il s'agit ici de profits et de parts de marché. Les échantillons sont utilisés, ils apportent une «valeur ajoutée de la vie» et constituent des «biovaleurs». La banque de sperme danoise Cyros International veille au renouvellement des générations dans le monde entier, les éjaculations d'étalons sont décisives pour les épreuves de saut, les supertaureaux favorisent les gains à la bourse, la cartographie génétique, les cellules souches dentales et le sang ombilical sont de bons placements.

L'image répandue de l'arche de Noé est simpliste, car les réservoirs de matières premières ont une croissance parallèle à l'exploitation abusive de la nature. La pratique de la collecte n'a de légitimité que parce que la destruction de l'environnement écologique et l'extinc- tion des espèces sont tolérées comme des phénomènes inéluctables. La résurrection en dehors des armoires blindées pourrait paraître illusoire, puisque les semences végétales conservées ex situ perdent leur pouvoir de germer sans leur environnement naturel. C'est un fait, les grandes banques de spermes profitent plus aux groupes semenciers qu'aux agriculteurs. Sans compter que les banques de données biologiques mettent en évidence un changement de valeurs radical. Les anciens critères de classement entre organique et inorganique, naturel ou artificiel, sont dépassés. La matérialité des organismes biologiques est transformée en texte codé. Les êtres vivants sont réduits à l'état de systèmes de communication, ils ne sont plus que des logiciels moléculaires, traités, lus, sauvegardés et recopiés à volonté comme de simples informations. Les plaques de Petri, sachets d'aluminium et biopsies présentés nécessitent des explications pour aller plus loin.

La brochure descriptive de l'exposition raconte l'histoire que cachent ces images. Nous découvrons des simulations informatiques de l'évolution, une microbiologie marine dans les abysses et des signatures biologiques extraterrestres de l'astrobiologie. Il n'y a jamais eu aussi peu d'explication de la «vie» qu'à l'ère de la biologie synthétique, de la médecine reproductive et de la bioinformatique. Peut-être faut-il chercher la vie complètement ailleurs. Le biologiste bâlois Adolf Portmann n'a cessé de mettre l'accent sur la part méconnue et mystérieuse des organismes vivants, acceptant parfois d'être considéré comme un Don Quichotte de l'univers technologique des laboratoires. Quarante ans plus tard, le jeune photographe Yann Mingard nous montre que la part lumineuse des visions progressistes de la médecine et de la technologie a aussi sa part d'ombre. La connaissance de la manipulation a un côté nécrophile, hostile à la vie. Si nous nous concentrons sur l'asservissement et la faisabilité et que nous exploitons sans scrupules l'abondance de ce qui existe, le prix que nous paierons à long terme sera effroyable.

Ceux qui souhaitent aborder ce sujet par le biais de la littérature peuvent lire Margaret Atwood. Cette Canadienne a toujours été fascinée par les évolutions sociales et les technologies informatiques et génétiques. Après Le Dernier Homme et Le Temps du Déluge, paraît en 2014, en allemand, le dernier volume de cette dystopie en trois parties, MaddAddam (Die Geschichte von Zeb). Les fils de notre époque actuelle y sont démêlés de main de maître, avec une grande intelligence. Et la fin reste ouverte, comme il se doit.

Erhard Taverna 